\title{
Human T-cell lymphotropic virus type I (HTLV-I) proviral DNA viral load among asymptomatic patients and patients with HTLV-I-associated myelopathy/ tropical spastic paraparesis
}

P.A. Montanheiro ${ }^{1}$,

A.C. Penalva de Oliveira ${ }^{3}$, M.P. Posada-Vergara ${ }^{3}$, A.C. Milagres ${ }^{2}$,

C. Tauil2 ${ }^{2}$ P.E. Marchiori ${ }^{2}$, A.J.S. Duarte ${ }^{1}$ and J. Casseb ${ }^{1,3}$
${ }^{1}$ Laboratório de Alergia e Imunologia Clínica e Experimental, LIM-56, Departamento de Dermatologia, ${ }^{2}$ Departamento de Neurologia, Hospital das Clínicas, Faculdade de Medicina, Universidade de São Paulo, São Paulo, SP, Brasil ${ }^{3}$ Instituto de Infectologia "Emílio Ribas", São Paulo, SP, Brasil

\section{Correspondence}

J. Casseb

Laboratório de Alergia e Imunologia Clínica e Experimental (LIM-56) Departamento de Dermatologia Faculdade de Medicina, USP R. Dr. Enéas de Carvalho, 500 Instituto de Medicina Tropical de São Paulo, Prédio II, 30 andar 05403-000 São Paulo, SP Brasil

Fax: +55-11-3081-7190

E-mail: j31@hotmail.com

Research supported by FAPESP, CNPq, and LIM-56.

Received January 20, 2004 Accepted May 3, 2005

Abstract

To evaluate the human T-cell lymphotropic virus type I (HTLV-I) proviral DNA load among asymptomatic HTLV-I-infected carriers and patients with HTLV-I-associated myelopathy/tropical spastic paraparesis (HAM/TSP), real time PCR using TaqMan probes for the pol gene was performed in two million peripheral blood mononuclear cells (PBMC). The albumin gene was the internal genomic control and MT2 cells were used as positive control. The results are reported as copies $/ 10,000 \mathrm{PBMC}$, and the detection limit was 10 copies. A total of 89 subjects (44 HAM/TSP and 45 healthy HTLV-I-infected carriers) followed up at the Institute of Infectious Diseases "Emilio Ribas" and in the Neurology Division of Hospital of Clínicas were studied. The asymptomatic HTLV-I-infected carriers had a median number of 271 copies (ranging from 5 to 4756 copies), whereas the HAM/TSP cases presented a median of 679 copies (5-5360 copies) in 10,000 PBMC. Thus, HAM/TSP patients presented a significantly higher HTLV-I proviral DNA load than healthy HTLV-I carriers ( $\mathrm{P}=0.005$, one-way Mann-Whitney test). As observed in other persistent infections, proviral DNA load quantification may be an important tool for monotoring HTLV-I-infected subjects. However, long-term follow-up is necessary to validate this assay in the clinical setting.

Human T-cell lymphotropic virus type I (HTLV-I) is the etiological agent of HTLVI-associated myelopathy/tropical spastic paraparesis (HAM/TSP) $(1,2)$. Ten to twenty million people are persistently infected with HTLV-I and are at risk of developing HAM/
Key words

- HTLV-I

- HTLV-I-associated myelopathy/tropical spastic paraparesis (HAM/TSP)

- HTLV-I DNA viral load ...................

TSP and adult T-cell leukemia/lymphoma worldwide. A high prevalence was found in intravenous drug users and in patients with sexually transmitted diseases. Although the majority are healthy, 2-5\% may develop HAM/TSP (3). 
HAM/TSP is a chronic debilitating inflammatory disease of the central nervous system characterized by axonal damage and demyelination, most pronounced in the midthoracic spinal cord (4). HAM/TSP patients mount a very vigorous antibody and cytolytic $\mathrm{T}$ lymphocyte $(5,6)$ response to HTLV-I. This shows that HTLV-I infection alone is not enough to cause HAM/TSP, but additional factors such as the virus-host interaction, HTLV-I proviral load, and HLA haplotypes, such as HLA*DR-A2 are also important (7).

In many viral infections, viral load may indicate the degree of replication and usually indicates the possibility of causing damage to the host over long periods of time. It has been well demonstrated that plasma viral load of human immunodeficiency virus type 1 (HIV-1) correlates to disease progression and is an important surrogate marker in predicting the development of acquired immunodeficiency syndrome (AIDS) (8).

Despite the large quantities of data regarding HIV and viral load for AIDS progression, few studies have been published regarding the viral load of HTLV-I and the clinical outcome (9). The major problem is that HTLV-I infection has a long incubation time and fewer than $5 \%$ of carriers will actually progress to the associated disease (3).

It has been previously demonstrated that the replication of HTLV-I is increased in HAM/TSP patients as compared with asymptomatic HTLV-I carriers $(10,11)$. However, this is not yet conclusive and the mechanisms of HAM/TSP development still continue to elude us. In this short communication, we present data on HTLV-I proviral load in asymptomatic and HAM/TSP patients from São Paulo, SP, Brazil.

All patients included in the study were followed at the "Emílio Ribas" Institute of Infectious Diseases and at the Neurology Section of "Hospital das Clínicas da Universidade de São Paulo". Blood samples were collected from 45 asymptomatic HTLV-Iinfected individuals and 44 patients with HAM/TSP. The HAM/TSP diagnosis was made by a neurologist according to World Health Organization diagnostic guidelines (12). The study was approved by the Ethics Research Committee of both institutions involved and all subjects gave written informed consent to participate. The subjects were diagnosed using standard protocols (ELISA HTLV-I/II Ortho D, Raritan, NJ, USA), Western blot (HTLV 2.4, Diagnostic Biotechnology, Singapore). The MT2 cell line was used as a positive control for HTLV-I.

Peripheral blood mononuclear cells (PBMC) from patients and controls were isolated from an acid-citrate-dextrose solution and separated by Ficoll density gradient centrifugation (Pharmacia, Uppsala, Sweden). The cells were washed with saline and pellets with $10^{6}$ cells were stored at $-70^{\circ} \mathrm{C}$ until use. DNA was extracted using a commercial kit (GFX Pharmacia, Uppsala, Sweden).

The forward and reverse primers used for HTLV-I DNA quantitation were SK110 (5'CCCTACAATCCAACCAGCTCAG-3', HTLV-I nucleotide 4758-4779 (GenBank accession No. J02029)), and SK111 (5'GTGGTGAAGCTGCCATCGGGTTTT-3', HTLV-I nucleotide 4943-4920). The internal HTLV-I TaqMan probe (5'-CTTTAC TGACAAACCCGACCTACCCATGGA-3') was selected using the Oligo (version 4, National Biosciences, Plymouth, MI, USA) and Primer Express (Perkin-Elmer Applied Biosystems, Boston, MA, USA) software programs and checked by a search of GenBank. The probe was located between positions 4829 and 4858 of the HTLV-I genome and carried a 5' reporter dye FAM (6-carboxy fluorescein) and a 3' quencher dye TAMRA (6-carboxy tetramethyl rhodamine). For quantification of the human albumin gene, the primers Alb-S (5'-GCTGTCA TCTCTTGTGGGCTGT-3') and Alb-AS (5'AAACTCATGGGAGCTGCTGGTT-3') 
and the albumin TaqMan probe (5'-FAMCCTGTCATGCCCACACAAATCTCT CCTAMRA-3') were used as described previously (13).

Albumin DNA was quantitated jointly in all samples in order to determine the amount of DNA used as an endogenous reference to normalize variations due to differences in PBMC counts or DNA extraction.

The 50- $\mu$ l PCR mixture for HTLV-I or albumin DNA amplification consisted of 10 liters DNA extract, primers SK110 and SK111 or Alb-S and Alb-AS (200 nM of each), 100 nM HTLV-I or albumin TaqMan probe, dATP, dCTP, and dGTP, each at a concentration of $200 \mathrm{nM}, 400 \mathrm{nM}$ dUTP, 5 $\mathrm{mM} \mathrm{MgCl} 2,0.5 \mathrm{U}$ uracil DNA glycosylase, $1.25 \mathrm{U}$ Taq platinum polymerase, and $1 \mathrm{x}$ PCR buffer. For both the HTLV-I and albumin DNA amplifications, after one cycle at $50^{\circ} \mathrm{C}$ for $2 \mathrm{~min}$ and one cycle at $95^{\circ} \mathrm{C}$ for 10 min, a two-step PCR procedure was used consisting of $15 \mathrm{~s}$ at $95^{\circ} \mathrm{C}$ and $1 \mathrm{~min}$ at $65^{\circ} \mathrm{C}$ for 45 cycles. Amplification and data acquisition were carried out using the I-Cycler Sequence Detector System (BioRad, Hercules, CA, USA).

For the albumin control we used PBMC from healthy individuals seronegative for HTLV-I/II and HIV-1 infection. These cells were separated on a Ficoll density gradient and counted at a concentration of $2 \times 10^{6}$ after serial dilution $\left(2 \times 10^{5}, 2 \times 10^{4}\right.$ and $2 \times$ $\left.10^{3}\right)$. MT2 cells were used as internal control and counted at a concentration of $10^{5}$, and serial dilutions of $10^{4}, 10^{3}$ and $10^{2}$ were performed. For the standard curve, we used HTLV-I- and HIV-1-negative samples of $2 x$ $10^{6}$ cells. DNA was diluted and used for the control of albumin (Figure 1A) (14), and the same procedure was applied to the MT2 cells (Figure 1B). Standard curves for HTLVI and albumin were accepted when the slopes were between -3.74 and -3.32 (corresponding to PCR efficiencies of 85 to $100 \%$ ) and the coefficients of correlation, $r^{2}$, were $>0.98$. The analysis was repeated when there was more than $30 \%$ variation between duplicate values of HTLV-I or albumin DNA copy numbers. The MT2 cell line (kindly provided by Dana Gallo, Viral and Ricketsial Disease Laboratory, Richmond, CA, USA) was used as a quantitation control in each run, and 2.4-3.3 HTLV-I copies/cells were considered to be acceptable results. The normalized value of HTLV-I proviral load was calculated as the ratio of (HTLV-I DNA average copy number/albumin DNA average copy number) $\times 2 \times 10^{6}$ and is reported as number of HTLV-I copies $/ 10^{6}$ PBMC (15).

Data were analyzed statistically by the one-way Mann-Whitney test and percentages were transformed for analysis. In both cases, $\mathrm{P}$ values $<0.05$ were considered to be statistical significant.

A total of 45 asymptomatic HTLV-Iinfected subjects and $44 \mathrm{HAM} / \mathrm{TSP}$ cases were studied. The asymptomatic group presented an average of 271 copies in 10,000 cells (range: 5 to 4756 copies), whereas the HAM/TSP group presented an average of 679 copies (range: 5 to 5360 copies) in 10,000 cells. HAM/TSP patients had a significantly higher number of HTLV-I copies than healthy carriers $(\mathrm{P}=0.005)$. Also, HAM/ TSP cases had 3-fold higher levels compared to the asymptomatic HTLV-I carrier group.

Despite some overlapping values, HAM/ TSP patients presented higher HTLV-I proviral DNA viral load than asymptomatic HTLV-I-infected carriers. As observed in other persistent infections, such as HIV-1 and hepatitis $\mathrm{C}$ virus, viral load is also important during HTLV-I infections and regarding their outcome. Unfortunately, longterm follow-up is necessary to discover new outcomes in HTLV-I-infected positive carriers. In fact, some studies have shown similar results $(16,17)$.

It is also possible that immune mediated disturbances are a major force that drives HAM/TSP immune pathogenesis. More recently, CD8+ T cells have been shown to 

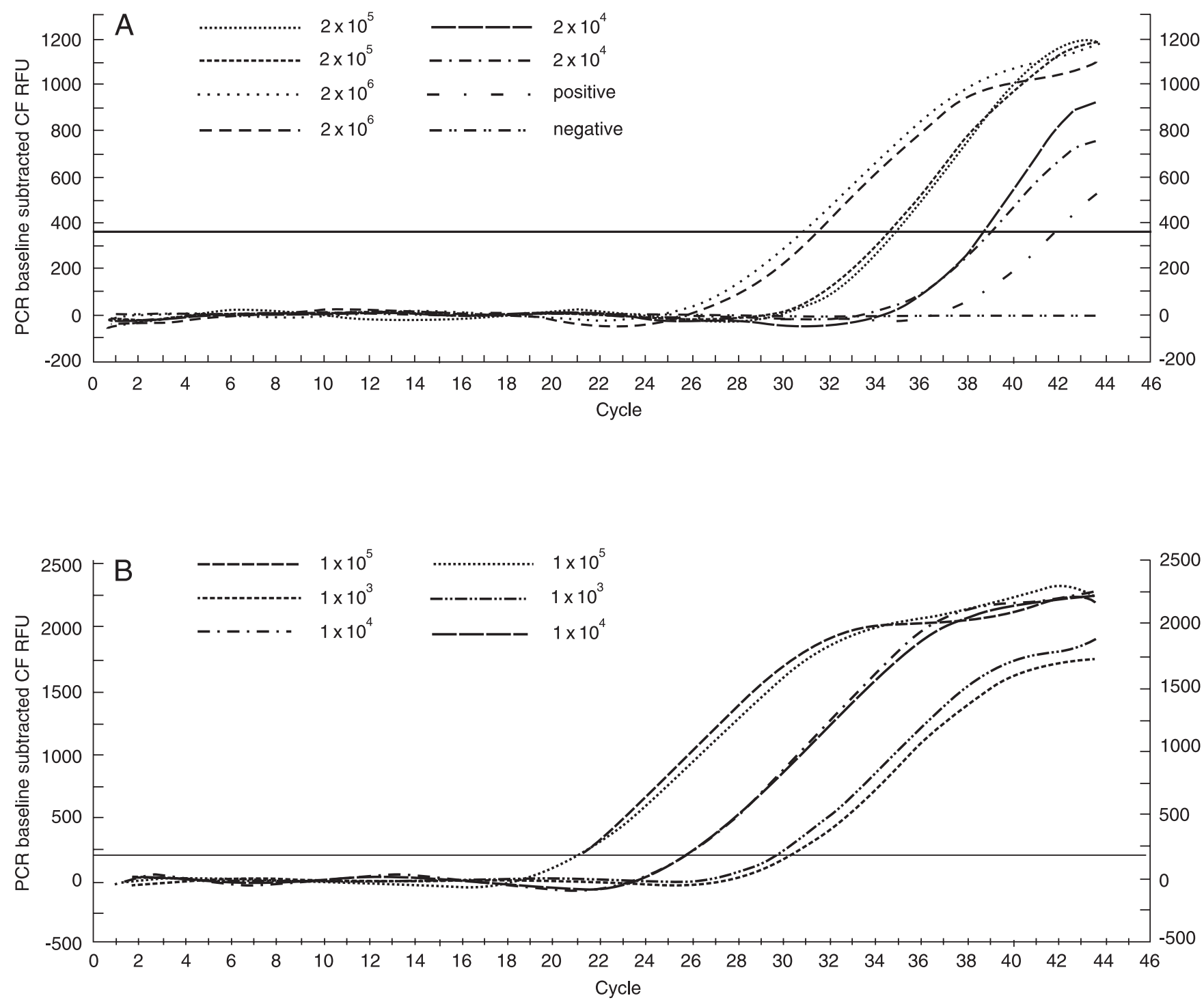

Figure 1. PCR amplification versus cycle for dilutions of DNA control $(A)$ and HTLV-I control using DNA from MT2 cells $(B)$. CF = coefficient; RFU = relative fluorescence units.

play an important role in HTLV-I disease progression in terms of cytotoxicity or soluble factor release (6). However, proviral DNA viral load may play a major role in this disorder. This finding only reflects the low pathogenicity of this virus. Moreover, viral association with disease development is highly influenced by HLA genetic background as well as by viral factors (18).

In the present study, we noted that some asymptomatic HTLV-I-infected individuals presented a higher viral load than HAM/TSP patients. More recently, it has been shown that $\mathrm{T} \mathrm{CD} 4+$ expressing tax protein may play a crucial role in explaining these findings, since these cells release higher levels of IFN- $\gamma$, which may explain most factors involved in the pathogenesis of HAM/TSP (19).

Moreover, HTLV-I-related diseases usu- 
ally occur 30-40 years after incubation (20) and few new cases of HAM/TSP have been reported. In our cohort, only one new recently HAM/TSP diagnosed case was noted despite 1200 persons-years of observation (data not shown). Thus, only long-term follow-up with larger numbers of asymptomatic subjects will elucidate the role of proviral DNA viral load as a surrogate marker for the progression of HTLV-I disease.

\section{Acknowledgments}

The authors wish to thank Ligia Fukumori (Laboratório de Alergia e Imunologia Clínica e Experimental, LIM-56, Departamento de Dermatologia, USP, São Paulo, SP, Brazil) for technical assistance, and Dana Gallo (Viral and Ricketsial Disease Laboratory, Richmond, CA, USA) who kindly provided the MT2 cell line.

\section{References}

1. Gessain A, Barin F, Vernant JC et al. (1985). Antibodies to human Tlymphotropic virus type-I in patients with tropical spastic paraparesis. Lancet, 2: 407-410.

2. Osame M, Usuku K, Izumo $S$ et al. (1986). HTLV-I associated myelopathy: A new clinical entity. Lancet, 1: 1031-1032.

3. Kaplan JE, Osame M, Kubota $\mathrm{H}$ et al. (1990). The risk of development of HTLV-I-associated myelopathy/tropical spastic paraparesis among persons infected with HTLV-I. Journal of Acquired Immune Deficiency Syndromes, 3: 1096-1101.

4. Iwasaki Y (1993). Human T cell leukemia virus type I infection and chronic myelopathy. Brain Pathology, 3: 1-10.

5. Shimamoto $Y$, Funai $N$, Watanabe $M$ et al. (1996). Increased production of interferon gamma but not interleukin 4 in human Tlymphotropic virus type I carriers. International Journal of Hematology, 64: 111-118.

6. Jacobson S (2002). Immunopathogenesis of human T cell lymphotropic virus type I-associated neurologic disease. Journal of Infectious Diseases, 186 (Suppl 2): S187-S192.

7. Hollsberg P \& Hafler DA (1995). What is the pathogenesis of human T-cell lymphotropic virus type I-associated myelopathy/tropical spastic paraparesis? Annals of Neurology, 37: 143-145.

8. Mellors JW, Kingsley LA, Rinaldo Jr CR et al. (1997). Plasma viral load and CD4+ lymphocytes as prognostic markers of HIV-1 infection. Annals of Internal Medicine, 126: 946-954.

9. Osame M (2002). Pathological mechanisms of human T-cell lymphotropic virus type l-associated myelopathy (HAM/TSP). Journal of Neurovirology, 8: 359-364.

10. Yoshida M, Osame M, Kawai H et al. (1989). Increased replication of HTLV-I in HTLV-I-associated myelopathy. Annals of Neurology, 26: 331-335.

11. Kubota R, Fujiyoshi T, Izumo S et al. (1993). Fluctuation of HTLV-I proviral DNA in peripheral blood mononuclear cells of HTLV-I-associated myelopathy. Journal of Neuroimmunology, 42: 147-154.

12. Osame M (1992). Mielopatia asociada con el HTLV-I (HAM/PET) en
Japon. In: Zaninovic V, Galindo J \& Blank A (Editors), Enfermedades Asociadas con el Virus HTLV-I. Fundación MAR, Cali, Colombia, 87-96.

13. Laurendeau I, Bahuau M, Vodovar N et al. (1999). TaqMan PCRbased gene dosage assay for predictive testing in individuals from a cancer family with INK4 locus haploinsufficiency. Clinical Chemistry, 45: 982-986.

14. Vet JA, Majithia AR, Marras SA et al. (1999). Multiplex detection of four pathogenic retroviruses using molecular beacons. Proceedings of the National Academy of Sciences, USA, 96: 6394-6399.

15. Dehee A, Cesaire R, Desire N et al. (2002). Quantitation of HTLV-I proviral load by a TaqMan real-time PCR assay. Journal of Virological Methods, 102: 37-51.

16. Nagai M, Usuku K, Matsumoto W et al. (1998). Analysis of HTLV-I proviral load in $202 \mathrm{HAM} / \mathrm{TSP}$ patients and 243 asymptomatic HTLVI carriers: high proviral load strongly predisposes to HAM/TSP. Journal of Neurovirology, 4: 586-593.

17. Yamano $Y$, Nagai $M$, Brennan $M$ et al. (2002). Correlation of human T-cell lymphotropic virus type 1 (HTLV-1) mRNA with proviral DNA load, virus-specific CD8(+) T cells, and disease severity in HTLV-1associated myelopathy (HAM/TSP). Blood, 99: 88-94.

18. Jeffery KJ, Usuku K, Hall SE et al. (1999). HLA alleles determine human T-lymphotropic virus-I (HTLV-I) proviral load and the risk of HTLV-I-associated myelopathy. Proceedings of the National Academy of Sciences, USA, 96: 3848-3853.

19. Furukawa Y, Saito M, Matsumoto W et al. (2003). Different cytokine production in tax-expressing cells between patients with human $T$ cell lymphotropic virus type I (HTLV-I)-associated myelopathy/tropical spastic paraparesis and asymptomatic HTLV-I carriers. Journal of Infectious Diseases, 187: 1116-1125.

20. Matsuzaki T, Nakagawa M, Nagai M et al. (2001). HTLV-I proviral load correlates with progression of motor disability in HAM/TSP: analysis of $239 \mathrm{HAM} / \mathrm{TSP}$ patients including 64 patients followed up for 10 years. Journal of Neurovirology, 7: 228-234. 